\title{
5. Thomson's Spears: Innovation and change in eastern Arnhem Land projectile technology
}

\author{
Harry Allen \\ University of Auckland, Museum Victoria, La Trobe University
}

\section{Introduction}

The 1960s was a lively time to be an undergraduate at the University of Sydney. The campus was in furore with demonstrations against the Vietnam War and freedom rides in favour of Aboriginal rights. If studying anthropology at Sydney was a privilege then experiencing visitors, cricket matches against The Australian National University and the academic salon life of Balmainmaintained by Les Hiatt, Betty Meehan and Rhys Jones - was to be in heaven. I remember the arrival of a PhD student, Nicolas Peterson, fresh from Cambridge, who quickly embarked on fieldwork at a newly established Aboriginal outstation at Mirrngadja, on the eastern margin of the Arafura Swamp in Arnhem Land.

Les Hiatt's and Nic Peterson's fieldwork in Arnhem Land demonstrated that Aboriginal hunter-gatherers in northern Australia continued to hunt and gather. This was a revelation - one that had a profound impact on the development of archaeology in Australia. Nic Peterson's theoretical orientation, at the time, could be described as cultural ecological — an approach that meshed with that of Rhys Jones, also from Cambridge, who adapted the Higgs-Jarman approach to palaeoecology to a form of palaeo-ethno-archaeology that has been glossed in the literature as the 'Sydney School' (Meehan and Jones 1988: viii).

By a further chance, in 1969, Rhys Jones, Nic Peterson and I ended up in the Research School of Pacific Studies at The Australian National University, pursuing, through quite different approaches, the contribution that Australian Aboriginal ethnography can make to an understanding of cultural ecology, and, in my own case, to archaeology. During these years, Nic Peterson wrote a number of influential papers in the field of ethno-archaeology $(1968,1970,1971$, 1973, 1976; Thomson 2003; White and Peterson 1969), using what has become known as the direct historical approach to analogical reasoning (Peterson 1971: 240; Stahl 1993: 242-4). 
In addition to his contribution to social anthropology and to Aboriginal rights (see Kubota, this volume), Nic Peterson's work on museum collections and the history of anthropology has been significant, particularly his championing of Donald Thomson and Thomson's collection of Aboriginal material culture, now held in the Melbourne Museum (L. Allen 2008; Peterson 1976; Rigsby and Peterson 2005). Thomson also was a pioneer of ecological studies and the ethnoarchaeological approach in Australia (Thomson 1939, 1949).

In 1971 and 1976, Nic Peterson discussed stability and change in Australian Aboriginal material culture. He put forward two significant ideas: first, that change in Aboriginal technologies was through 'substitution', through which, over time, more efficient forms replaced older and, presumably, less-efficient forms; and, second, that in cases where greater efficiency could not be assumed, a change could be stylistic in nature (for a discussion of Yolngu perceptions of 'change' in regards to non-material circumstance, see Barber, this volume).

Peterson's conclusions regarding efficiency and technological change were based on observations made at Mirrngadja, at a time when iron spear tips had replaced those made of stone, bone and wood, with these in turn being replaced by .22 rifles and shotguns. In his article entitled 'Ethno-archaeology in the Australia iron age', Peterson noted that on entering a camp:

The impedimenta of European culture [are] immediately noticeable... Blankets, tent-flies, suit-cases, mosquito nets, clothing, guns, billy-cans and discarded tins are the most obvious. Besides these additions, there are other items that fit more naturally into the scene as substitutes. Hunting spears, once armed with wooden or stone points, now have blades fashioned from car springs; the bone and wooden prongs of the fish spears are replaced by fence wire; digging sticks, formerly of ironwood are now made from iron rods and all axes are of steel. (Peterson 1976: 265-6)

Peterson (1976: 266-7) argued that the process of technological innovation was one of substitution, where new items were adopted because they fitted existing needs, were easier to obtain or produce, or did the job more efficiently. The hypothesis that change in Aboriginal technical systems is through replacement with functional equivalents would appear to be confirmed by the fact that, since the 1970s, spears have mostly been replaced with guns and hunting is now carried out using four-wheel-drive vehicles (Altman and Hinkson 2007).

Nic Peterson also put forward a set of ideas concerning the adoption of small stone projectile points, which first appear in the archaeological record about 5000 years ago (Mulvaney and Kamminga 1999: 237). Based on the fact that Aboriginal people had successfully hunted and gathered for thousands of years 
prior to this, Peterson (1971: 244) argued that this change did not necessarily represent an increase in hunting efficiency and that stone projectile points could have been adopted for other reasons. He concluded that stone projectile points were not required to successfully exploit the Australian environment. Noting this statement, other authors have argued that as stone projectile points cannot be shown to be necessary in a functional sense, they might best be seen as a 'stylistic phenomenon' (White and O'Connell 1982: 124).

In this chapter, the strands of ethno-archaeology and material culture studies will be drawn together through an analysis of a collection of spears obtained by Donald Thomson from eastern Arnhem Land. Thomson's collection is an important one as it was made at a time when rapid changes were taking place in eastern Arnhem Land, stimulated by trading within Aboriginal Australia and contact with Europeans and with visiting fishermen-previously Macassans, but more latterly Japanese (Thomson 1949). Thomson's collection contains a number of types of spears and spear-throwers and as such demonstrates a degree of complexity and, in the case of spears with metal heads, the adoption of new forms. An analysis of this collection provides the opportunity to test Peterson's arguments regarding the nature of technological change within Aboriginal material culture as well as increasing our understanding of how technological innovations occur in hunting and gathering societies. The purpose here is not to criticise ideas put forward more than 30 years ago, but rather to examine how a formal analysis of the Thomson collection of spears from eastern Arnhem Land might further our understanding of change in Aboriginal technologies.

\section{The Thomson Collection of Spears from Eastern Arnhem Land}

The Thomson collection of spears at Melbourne Museum consists of 863 spears or component parts collected by Donald Thomson from eastern Arnhem Land between 1935 and 1943 (L. Allen 2008). This collection was the subject of BA Honours thesis research by Annette Berryman (1980). Copies of Berryman's original data sheets were available at Melbourne Museum and, with Berryman's permission, this reanalysis is based on that research.

Thomson's collection is not a natural collection in the sense that it does not represent all the spears made by a single spear maker, all the spears from a single camp, or all spears from a single region of northeast Arnhem Land. Rather, Thomson set himself the task of bringing together a representative collection of spears and spear types. He purchased spears when Aboriginal men were willing to part with them and he made special efforts to obtain rare or unusual specimens by offering quantities of tobacco, fish hooks, wire or flour-articles 
that a reluctant seller might find hard to resist. Most spears were collected during the dry seasons of 1935 and 1936, with activities tapering off in 1937, when Thomson considered that he had a good range of variation of each type of spear available (Berryman 1980: 5-11). The percentages of spears in the collection from different areas of Arnhem Land are shown in Figure 5.1.The nature of the collection, then, means that we have to take some care in extracting meaning from it. On the other hand, it would appear likely that the number of different types of spears in the collection bears some relation to their availability, such that valuable spears passed into the collection in small numbers, while common and easily replaced spears predominate.

The first task in the formal analysis of any artefact is to create a workable typology - one that groups the data into sensible categories and allows further questions to be asked of them. There are many ways to create a typology of spears. Except for Davidson's (1934) typology of spears constructed to test his geographical theories, however, most classifications of Aboriginal spear forms have been unsuccessful (for example, Spencer 1915; Warner 1937). Following Cundy's (1989) innovative approach to the study of Australian projectile technology, factors that determine the performance qualities of projectiles are taken to be the most important. The typological system adopted here takes the nature of the spearhead as its initial defining feature. This is then broken down through further analysis of different shaft types. As such, this classification combines head and shaft types. The formal qualities of mass, length, density and thickness of the head and shaft largely determine the balance and performance characteristics of each spear type (cf. Warner 1937: 485-7). Some functional types (for example, fishing spears) were also distinguished but are not considered here (see Note 1).

The major types of spears in the Thomson collection distinguished here (see Figure 5.2) are discussed below. ${ }^{1}$

1. Spears with hardwood heads

- one-piece barbed and unbarbed spears

- composite, barbed spears

- composite, spears with unbarbed, blade-like heads.

2. Spears with stone heads.

3. Spears with metal heads.

4. Dart-type spears with plain hardwood heads.

1 The Thomson collection also contains spears with miscellaneous heads (stingray barbs, bird-bone points and others) as well as fishing spears and harpoons. While these are an important part of the collection, they are not discussed here for reasons of space. Except for harpoons - which are spears only in the general sense - for statistical purposes, fishing spears and those with miscellaneous heads are included in Tables 5.1 and 5.4. 


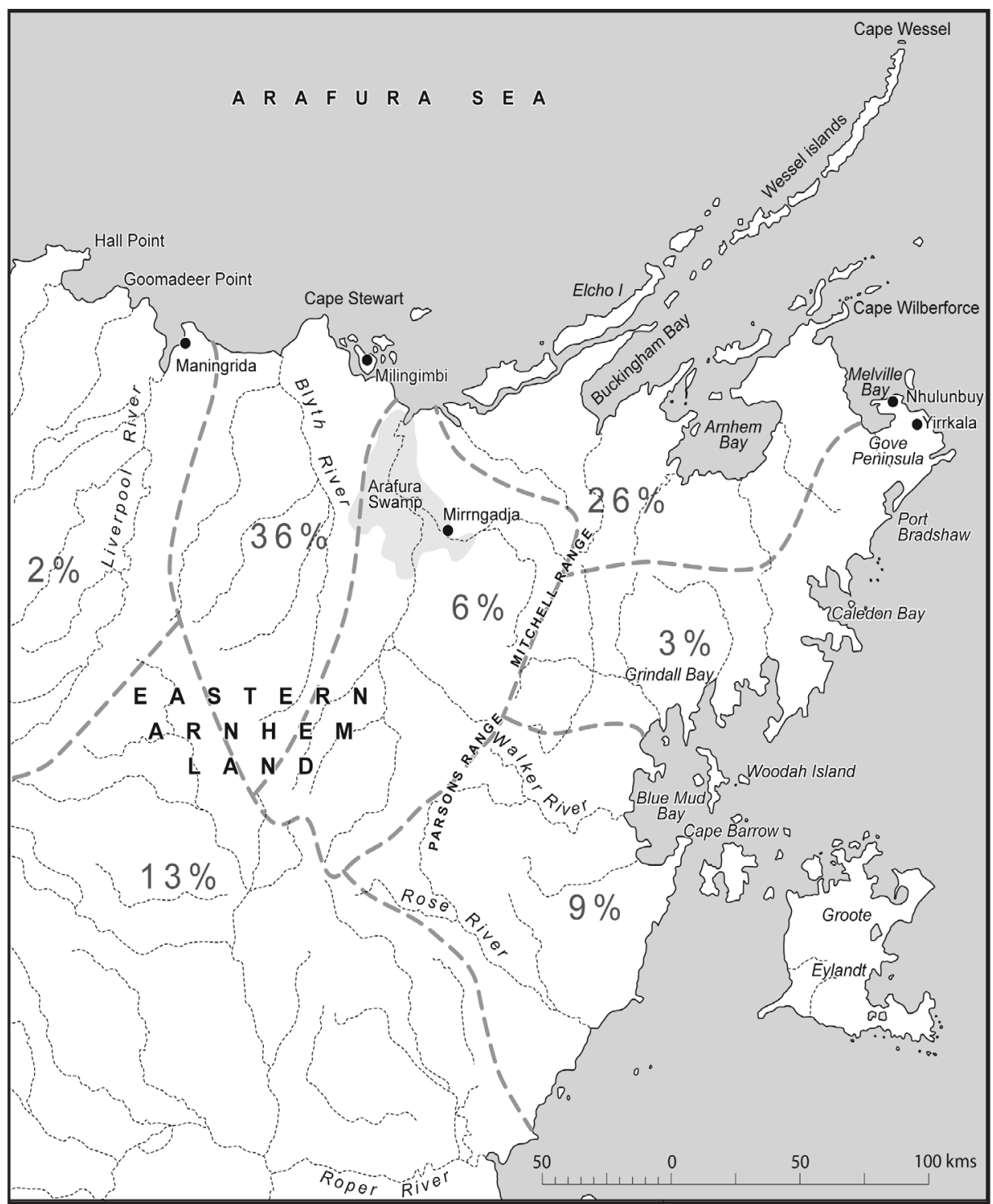

Figure 5.1 Spears from different areas of Arnhem Land in the Thomson collection

Recalculated from data assembled by Berryman (1980); map by Peter Quinn and Briar Sefton, University of Auckland. 
A

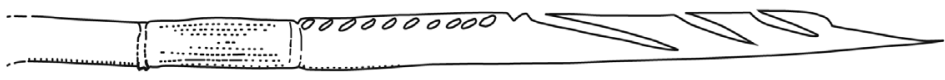

B

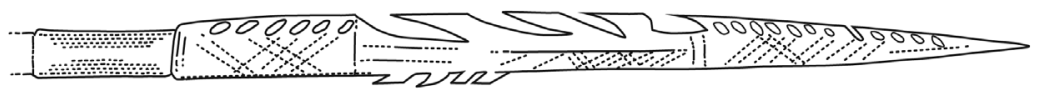

C

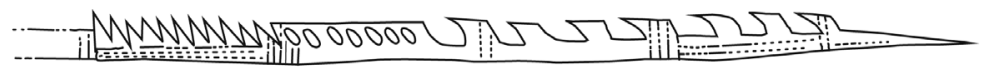

D

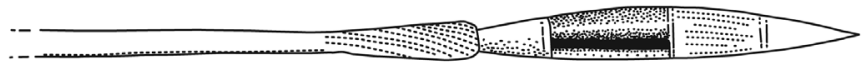

$\mathrm{E}$

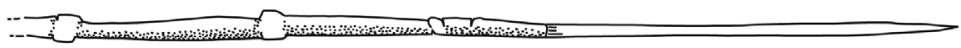

F

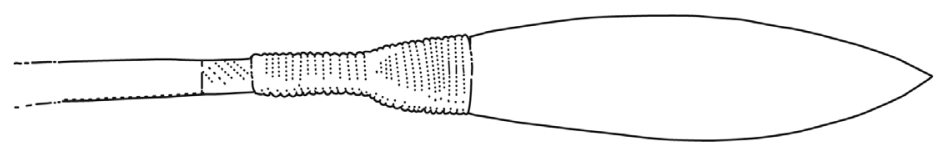

G

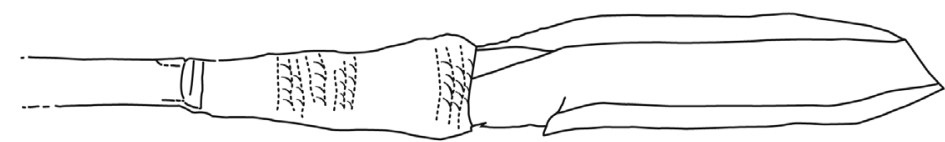

H

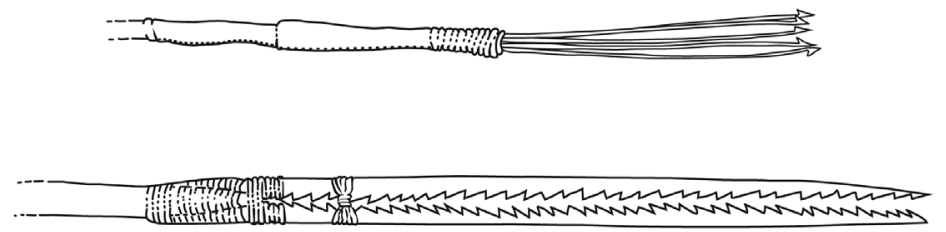

I

Figure 5.2 Types of spears in the Thomson collection, morphological/ functional categories. Spears with hardwood heads, A-C; spear with blade-line head, D; dart-like spear, E; metal head, F; stone head, G; fishing spears, $\mathrm{H}$ and $\mathrm{I}$.

Drawn by Peter Quinn and Briar Sefton, University of Auckland, after Berryman (1980). 
(Ai) One-piece hardwood spears, barbed and unbarbed $(n=19)$

There is a single example of a one-piece, unbarbed hardwood spear in the collection (MV 1752), recorded as coming from the mouth of the Roper River. This example has a recessed butt for use with a spear-thrower. Barbed onepiece hardwood spears have a long barbed head, usually on one side only. The barbs are often referred to as 'hooks', and Levitt $(1981$ : 26-7, 108) notes that on Groote Eylandt, 'hooked' spears with a variety of forms were individually carved from a single piece of Darwin stringy-bark (Eucalyptus tetrodonta). Warner (1937: 488) states that this spear is used almost entirely for fighting and that in recent years (that is, by the 1930s) these had gone out of general use and were manufactured mostly as a demonstration of carving skill. He (1937: 488) observed that when one-piece spears break, they are converted into a composite spear through the addition of a hafted head.

\section{(Aii) Composite spears, shaft plus barbed hardwood-head spears (n $=117$, Figure 5.2, $\mathrm{A}-\mathrm{C}$ )}

Because they represent a large and highly variable category, spears with detachable hardwood heads have given previous analysts the most difficulty (cf. Warner 1937: 485-9). Thomson and Warner provide Aboriginal terms for a wide variety of hardwood heads depending on the nature of the barbing, whether it is on one or both margins, unbarbed and blade-like, bifurcated or double pronged or, even, whether the barbs are fully or partially cut, as in the 'eyelet' or 'lace' types (Thomson, Field notes 1280-2, 1290-2, 1306-8 [1936 and 1942]; Warner 1937: 487). Cundy (1989: 109) believes that the complex variations in head form and terminology have more to do with socio-ideological than purely technical factors, probably as a demonstration of carving skill or as an indication of an individual maker. While the overall spear could be manufactured to conform with performance criteria, beyond this there is considerable scope for inventive barbing designs. Hardwood heads might be attached to a number of different shaft materials (hardwood 36, per cent; softwood, 22 per cent; reed/bamboo 17 per cent; and unidentified, 25 per cent). Hooked spears with barbed hardwood heads might be barbed on a single margin, both margins, or else are bifurcated. The majority are barbed on a single margin only.

(Aiii) Composite spears with unbarbed, blade-like heads ( $\mathrm{n}=4$, Figure 5.2, D)

Falkenberg (1968: 20), Levitt (1981: 29) and Thomson (Notes with spear MV 1913) suggest that this is a hardwood variant or forerunner of the metal 'shovel' spear, which it resembles in shape and size. Warner (1937: 487) states that a flat wooden-bladed head was used almost entirely for fighting, though Thomson (Notes, 1292 [1936]) describes these spears as both hunting and fighting spears. 
Ethnography and the Production of Anthropological Knowledge

\section{(B) Stone-head spears ( $\mathrm{n}=49$, Figure 5.2, G)}

Given that there are a number of different types of stone projectile points known ethnographically and archaeologically from northern Australia (H. Allen 1994), it is important to note that the stone spearheads being discussed here are those known as 'leilira' blades (cf. Thomson, 'ngämbi lirrä-stone spearheads'), also termed large blades. These spear points are long (60-200 mm in length) pointed flakes, with a triangular cross-section, having been produced from large blocky cores with a minimum of retouch (Jones and White 1988: 80). Warner (1937: 485) describes spears with these spearheads in some detail. He notes shafts were made of Eucalyptus, cane or mangrove, while Thomson (Field notes, 1285 [1936]) states that ngämbi lirrä (stone spearheads) were most commonly hafted to light warda warda shafts identified as Macaranagatanarius and fixed with beeswax and twine to facilitate easy attachment and detachment (Berryman 1980: 26). Thomson (1949: 65, 73) discusses the production of these large blades at the Ngilipitji quarry and their role in a ceremonial exchange system that distributed them across Arnhem Land. Further discussion of quarries, trade and the attribution of supernatural powers to these stone points can be found in $\mathrm{H}$. Allen (1994) and Jones and White (1988).

\section{(C) Metal-head spears ( $\mathrm{n}=43$, Figure 5.2, F)}

This spear is defined in terms of a metal blade, or spike, used as its head, excluding the wire prongs on fishing spears. Rounded metal head shapes predominate. These are the famous 'shovel-nosed' spears of Arnhem Land, which made use of iron or other metal originally obtained from the Macassans (Berndt and Berndt 1964: 102, 424; Levitt 1981: 30). Thomson (1949: 71) notes that ironheaded spears were traded from eastern Arnhem Land inland and south to the Roper River area. The metal blade is attached to the shaft via a socket made of fibre string and beeswax, which allows the blade to be removed and carried separately and used as a knife, when required (Thomson, Field notes, 20 August 1935). Predominantly light shafts made of softwood or cane are associated with this type of spear.

\section{(D) Dart-type spears with plain hardwood heads ( $\mathrm{n}=34$, Figure} $5.2, \mathrm{E})$

A number of authors separate this type (Falkenberg 1968: 21; Levitt 1981: 28; Thomson, Field notes, 1293; Warner 1937: 486-7). All note that this spear has a reed/bamboo shaft and a thin pointed hardwood head and, second, that there is a size variation between a larger form and an ultra-light, short dart-type spear. Falkenberg (1968: 21-3) observed that small and large variants of this spear type were the commonest types made in north-western Australia. 


\section{Composition of the Collection}

The number of spears of each type in the collection is shown in Table 5.1.

Levitt (1981: 25) notes that Groote Eylandt Aborigines divide their spears into those made from a single piece of wood and those having the head separate from the shaft. Similarly, Davidson (1934), and others, distinguishes one-piece spears from composite spears - that is, those with a shaft and a separate headarguing that the distinction has evolutionary significance. While there might have been temporal differences in the first appearance of these forms (see Walsh and Morwood 1999: 54-5), from a performance point of view, a one-piece hardwood spear is likely to demonstrate similar technological characteristics to composite two-piece hardwood spears of similar dimensions. Table 5.1 provides information on the length, mass and centre of balance for the spears in the collection. One-piece hardwood and composite (shaft plus detachable hardwood head) spears are closely comparable in all dimensions.

Table 5.1 Number, percentage and metrical characteristics of spear types in the Thomson Collection (MV)

\begin{tabular}{l|l|l|l|l|l}
\hline $\begin{array}{c}\text { Morphological/ } \\
\text { functional category }\end{array}$ & No. & Percentage & $\begin{array}{c}\text { Mean } \\
\text { length(cm) }\end{array}$ & $\begin{array}{c}\text { Mean } \\
\text { mass(g) }\end{array}$ & $\begin{array}{c}\text { Centre } \\
\text { of } \\
\text { balance }\end{array}$ \\
\hline One piece, hardwood & 19 & 7 & 256 & 330 & 0.45 \\
\hline Hardwood head & 121 & 42 & 272 & 328 & 0.41 \\
\hline Stone head & 49 & 17 & 261 & 362 & 0.29 \\
\hline Metal head, shovel spear & 43 & 15 & 268 & 480 & 0.28 \\
\hline Dart-type head & 34 & 12 & 207 & 125 & 0.36 \\
\hline Fishing & 12 & 4 & 280 & 346 & 0.34 \\
\hline Miscellaneous & 8 & 3 & 243 & 273 & 0.39 \\
\hline Total/average & 286 & 100 & 255 & 321 & 0.36 \\
\hline
\end{tabular}

Note: The hardwood-head category includes those with blade-like heads.

Source: Recalculated from data collected by Berryman (1980).

Information about shaft materials is restricted to the general categories hardwood, softwood or cane/bamboo. Shaft materials for composite hardwoodhead spears were identified by Thomson in 88 of 117 cases. Most identified ${ }^{2}$ shafts (42, or 48 per cent) are of hardwood, with the rest being about equally divided between softwood (20, or 23 per cent) and cane/bamboo (26, or 30 per cent). Table 5.2 compares the length, mass, centre of balance, shaft length and head lengths of hardwood-headed spears made with different shaft materials.

2 The figures for identified shaft types differ from those presented in Tables 5.3 and 5.4 because the tables include spears in the 'unknown' category. 
Hardwood, softwood and cane bamboo spears are closely comparable in all dimensions, except that those with cane/bamboo shafts are about two-thirds of the weight of spears using other materials.

Table 5.2 Characteristics of composite spears with hardwood heads, including blade-like heads, divided into different shaft types

\begin{tabular}{|c|c|c|c|c|c|c|}
\hline \multicolumn{7}{|c|}{ Hardwood heads } \\
\hline Shaft material & & $\begin{array}{c}\text { Total } \\
\text { length } \\
(\mathrm{cm})\end{array}$ & $\begin{array}{c}\text { Mass } \\
\text { (g) }\end{array}$ & $\begin{array}{c}\text { Centre of } \\
\text { balance } \\
\text { (proximal) }\end{array}$ & $\begin{array}{c}\text { Shaft } \\
\text { length } \\
\text { (cm) }\end{array}$ & $\begin{array}{c}\text { Head } \\
\text { length } \\
\text { (cm) }\end{array}$ \\
\hline & No. & Mean & Mean & Mean & Mean & Mean \\
\hline Hardwood & 34 & 261 & 347 & 0.46 & 208 & 53 \\
\hline Reed/bamboo & 17 & 271 & 219 & 0.40 & 233 & 38 \\
\hline Softwood & 40 & 282 & 340 & 0.36 & 234 & 48 \\
\hline Unknown & 30 & 276 & 344 & 0.40 & 227 & 49 \\
\hline Total/average & 121 & 271 & 323 & 0.41 & 223 & 48 \\
\hline
\end{tabular}

Source: Recalculated from data collected by Berryman (1980).

Relative to hardwood spearheads, stone blades are quite heavy. The main effect of the introduction of these spearheads was a small (10 per cent) increase in the weight of the spear and a shift in the centre of balance towards the proximal (head) end. Where we know the shaft material used for stone-headed spears, it is overwhelmingly softwood ( $\mathrm{n}=31,80$ per cent) with a few hardwood shafts ( $\mathrm{n}=8,20$ per cent). This suggests the selection of the lighter wood to partly compensate for the increased weight of the stone heads.

Metal-headed spears are the same length as other spear forms but they are nearly 1.5 times heavier (Table 5.1). Almost all of the weight in these spears comes from the metal head itself. This must have put extreme pressure on spear-throwers. Where the shaft material is identified for these spears, it is mostly of lighter materials — softwood ( $\mathrm{n}=14,54$ per cent) and cane/bamboo $(\mathrm{n}=8,31$ per cent) — with only a minority of shafts being of hardwood ( $\mathrm{n}=4,15$ per cent).

In contrast, the small darts are a light to ultra-light technology used with a goose spear-thrower. ${ }^{3}$ These spears are simple to make and easy to carry. They were used for feuding. Tindale (1925: 98) observed that the use of light bamboo-shafted spears by the east Arnhem Landers gave them an advantage over people from Groote Eylandt, who used heavier spear forms. Cundy (1989: 115-16, 119-20) states that there are similarities between the spears of northwestern Australia and those used in Arnhem Land, including the specialised

3 Goose spear-throwers are so named not because they were part of a specialised goose-hunting technology, but because the cement peg together with the shaft gave the spear-thrower a goose-like appearance. Davidson (1936: 476) termed them 'goose-necked' spear-throwers. Goose spears are the light dart-type spears used with a goose spear-thrower. 
goose spears (see Note 3). He (1989: 115) notes, 'a further advantage of using bamboo shafts is that because of their lightness and rigidity they may be used with relatively heavy heads, drawing the centre of gravity towards the tip and ensuring higher trajectory stability without affecting the shaft's ability to absorb and release strain energy'. Falkenberg (1968: 21), Levitt (1981: 28), Thomson (Field notes, 1293 [1936]) and Warner (1937: 486-7) divide this spear type into larger and smaller varieties. Figure 5.3 provides information on dart-type spears in terms of their relative mass and shows that these spears fall into two groups: a medium to light group ( $\mathrm{n}=16$, mean mass $199 \mathrm{~g}$, mean length $262 \mathrm{~cm}$ ) and a very small dart $(\mathrm{n}=18$, mean mass $60 \mathrm{~g}$, mean length $157 \mathrm{~cm})$. Thomson records an informant discussing these two types of spears in the following terms: 'We liken the flight of these spears to fine rain - rain just starting - and the bigger ones of similar form to heavy N.W. rain' (Field notes, 1293 [1936]). These darttype spears were distributed from north-western Australia to central Arnhem Land and Thomson observed that the 'true makers' of these spears were from the Glyde River, and they made use of reeds from the Arafura Swamp. This alerts us to the importance of trading relationships in this part of Australia. It should also be noted that Bambusa arhnemica grows only in the wetter parts of the Northern Territory and that access to this shaft material in eastern Arnhem Land was entirely through trade (Franklin 2008: Figure 1, p. 186).

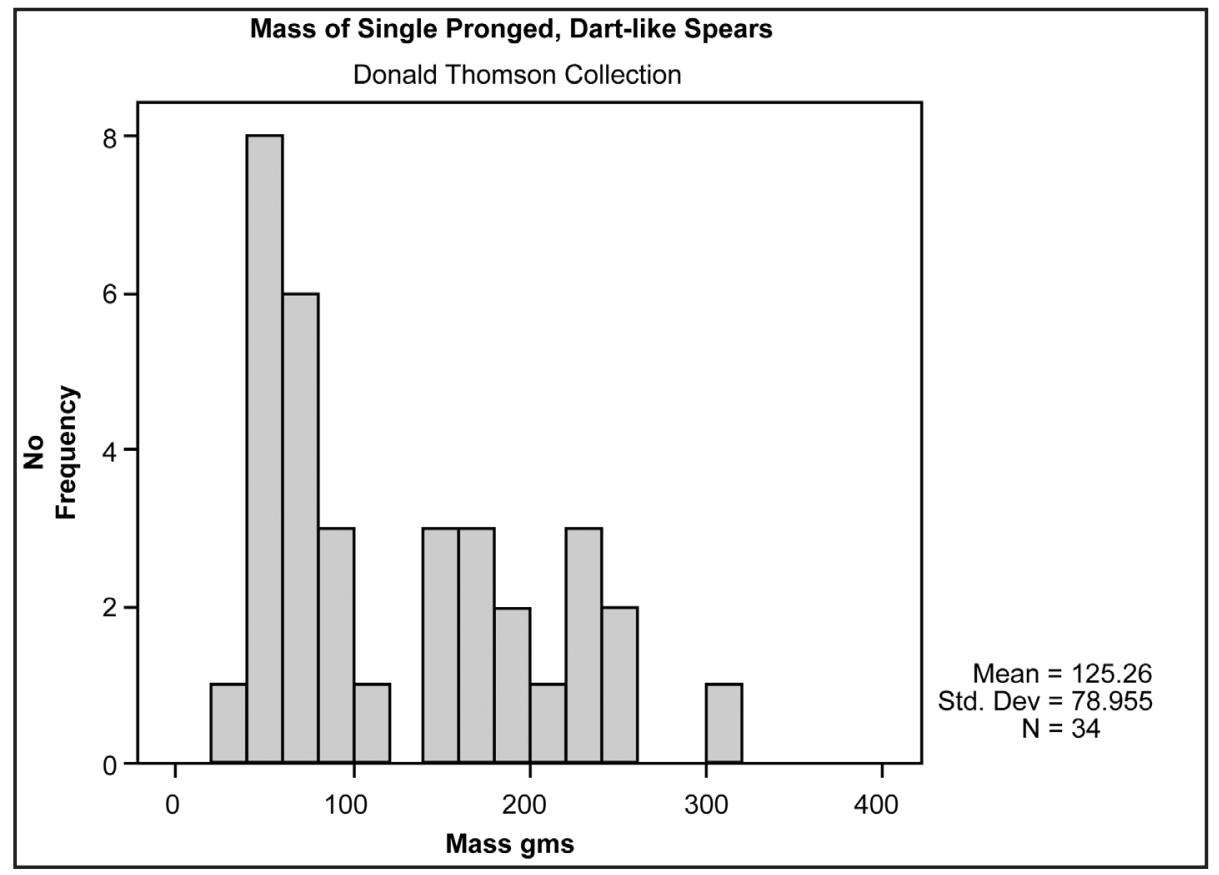

Figure 5.3 Distribution of dart-like spears with plain hardwood heads, number against mass, calculated in $20 \mathrm{~g}$ intervals, $0-400 \mathrm{~g}$

Recalculated by Daniel Parker from Berryman (1980) data; illustration by Daniel Parker and Briar Sefton, University of Auckland. 


\section{Spear-throwers}

While it is always useful to discuss Aboriginal projectile technology through a consideration of spears and associated spear-throwers, often spears and spear-throwers were collected separately (Cundy 1989). This was the case with Thomson's collection. As a result, information about which spear-throwers go with which spears - either from direct observation or from museum collections - is limited.

Cundy (1989: 104-23) identifies a number of spear-thrower types for Arnhem Land

1. north Australian notched lath spear-thrower

- east Arnhem Land notched lath spear-thrower

2. north Australian cylindrical spear-thrower

3. goose spear-thrower (see Note 3).

The notched lath spear-thrower can be described as a flattened shaft with parallel or converging sides, with notches cut on either side of the proximal end to form a grip. The east Arnhem Land notched lath form is shorter and heavier and has curved lateral margins and underdeveloped notching (Cundy 1989: 107). Cundy suggests that this form is a relatively late introduction - one associated with heavy spears with metal heads.

The spear-thrower used most often prior to the introduction of the lath spearthrower was the north Australian cylindrical spear-thrower consisting of a long hardwood stick with a round cross-section, which tapers towards the distal end and has a peg attached with a knob of resin. There is usually a fringe of tassel attached to the proximal end (Cundy 1989: 104).

Goose spear-throwers are cylindrical in form. They are used with very light dart-type spears and are incapable of being used with heavier spears. They have a thin cylindrical shaft of wood or bamboo. Cement is worked to form a rim towards the proximal end and the peg is made entirely of cement.

\section{Innovation and the Complexity of Spears in the Thomson Collection}

It is possible to draw a number of conclusions regarding the spears in this collection. First, the complexity of the assemblage is more apparent than real-partly a product of the typology used. Composite spears with detachable hardwood heads, barbed one-piece hardwood spears and stone-headed spears are comparable in terms of mass, length and centre of balance-factors that determine their performance characteristics. These are similar forms of spears with long, simple hardwood, softwood or cane shafts. Together these generalised fighting/hunting spears make up 66 per cent of the collection. 
Second, this technology represents a considerable number of innovations: detachable heads, whether hardwood, stone or metal; different attachment architectures; fixatives, whether soft beeswax or hard cypress-pine gum; bindings; sinew and twine; and, finally, different wood types for shafts, heads and spear-throwers. Wood species used in the construction of spears and spearthrowers in Arnhem Land are listed in Table 5.3. Cundy (1989: 110) notes that Arnhem Land possesses a number of tree and cane types capable of providing high-quality spear shafts. The trick was to get shafts that were long, straight and strong, ones that could be scraped down to the required thickness with a minimum of effort. The hardwood, softwood and bamboo shafts used for these spears represent such a cost-saving outcome.

Table 5.3 Woody species used in spear manufacture

\begin{tabular}{|c|c|c|}
\hline Use & Species & Common name \\
\hline \multirow[t]{8}{*}{ Light spear shafts } & Callitris intratropica & Cypress pine \\
\hline & Polyalthia nitidissima & Yellow-flowered jungle tree \\
\hline & Macaranga tanarius & Spear bush \\
\hline & Hibiscus tiliaceus & Yellow hibiscus \\
\hline & Thespesia populnea & Pacific rosewood \\
\hline & Brachychiton diversifolium & Kurrajong \\
\hline & Bambusa arnhemica & Arnhem Land bamboo \\
\hline & Phragmites karka & Cane grass \\
\hline \multirow[t]{3}{*}{ Heavy spear shafts } & Casuarina equisetifolia & Whistling tree \\
\hline & Lumnitzera racemosa & Good mangrove \\
\hline & Eucalyptus tetrodonta & Stringy-bark \\
\hline \multirow[t]{4}{*}{ Hardwood spearheads } & $\begin{array}{l}\text { Erythrophleum } \\
\text { chlorostachys }\end{array}$ & Cooktown ironwood \\
\hline & Acacia aulacocarpa & Broad-leaved wattle \\
\hline & Acacia multisiliqua & Small-ball wattle \\
\hline & Premna integrifolia & Mangrove berry \\
\hline \multirow[t]{3}{*}{ Lath spear-thrower } & Callitris intratropica & Cypress pine \\
\hline & Hibiscus tiliaceus & Yellow hibiscus \\
\hline & Alphitonia excelsa & Red ash \\
\hline Cylindrical spear-thrower & Eucalyptus tetrodonta & Stringy-bark \\
\hline
\end{tabular}

Sources: Based on information from Franklin 2008; Levitt 1981; Specht 1958, 2006; Yunupingu et al. 1995. 
Third, the continued production of spear-thrower-capable one-piece hardwood spears in Arnhem Land indicates that the introduction of the spear-thrower caused adjustments to be made to this technology rather than its replacement with new forms. The fact that carving one-piece spears - a time-consuming activity - was going out of fashion only in the 1920s would seem to confirm this. The retention of the older forms and their adjustment to fit in with the requirements of a new technology are not so unusual in the history of technical change. Automobiles retained the axles and leaf springs of horse-drawn carts until relatively late in the twentieth century.

Finally, Cundy (1989: 116-23) makes the further observation that, for the most part, north Australian spear technologies have not taken full advantage of the innovations made available to them through the adoption of the spear-thrower. As we have seen above, instead of producing a low-energy/high-velocity projectile system, an older high-energy/low-velocity system has been adjusted towards the middle of the high-energy-low-energy spectrum. It is a technology of a general rather than a specialised nature with fairly wide tolerances of both function and form. This is something that fits with individual men making their own spears, where each spear is the outcome of quite complex choices of shaft, head, attachment and mastic forms, with adjustments being made to achieve a spear within the weight and strength tolerances required.

Aspects of the spear assemblage that go against these generalisations are spears with metal heads, which represent the heaviest end of the north Australian spear spectrum (mean $=480 \mathrm{~g}$ ), and the dart-type spears, which represent the lightest end $($ mean $=125 \mathrm{~g})$.

Metal-headed spears were used for large targets: humans, large kangaroos, wild cattle and possibly buffalo. Aborigines responded quickly to the availability of this new material, attaching them mostly to light softwood or bamboo/cane shafts (Table 5.4). Beyond their heaviness, which was only partly offset by being attached to light shafts, spears with metal heads are similar in overall design, shaft and attachment form to other spears in this armoury, particularly those with stone heads. Both metal and stone heads were mounted using twine and soft beeswax - an innovative attachment and one that enabled heads to be carried separately from the shafts and mounted when required. The effect of the introduction of metal heads was one of adjusting the parameters of the existing technology to accommodate this change. Cundy's argument (1989: 107) that the shorter east Arnhem Land notched lath spear-thrower was a response to the introduction of the heavy metal-tipped spears is a case in point, demonstrating how the existing notched lath spear-throwers were strengthened by making them shorter and heavier to withstand additional forces associated with the heavier spears. 
Table 5.4 Spear shaft types in terms of spearheads as a percentage of overall spear types

\begin{tabular}{|c|c|c|c|c|c|}
\hline \multicolumn{6}{|c|}{ Shaft material } \\
\hline $\begin{array}{c}\text { Morphological/ } \\
\text { functional category }\end{array}$ & No. & $\begin{array}{c}\text { Hardwood } \\
(\%)\end{array}$ & $\begin{array}{c}\text { Reed/ } \\
\text { bamboo } \\
(\%)\end{array}$ & $\begin{array}{c}\text { Softwood } \\
(\%)\end{array}$ & $\begin{array}{c}\text { Unknown } \\
(\%)\end{array}$ \\
\hline One piece & 19 & 100 & & & \\
\hline Hardwood barbed heads & 117 & 36 & 17 & 22 & 25 \\
\hline Hardwood blade heads & 4 & & & 100 & \\
\hline Stone heads & 49 & 16 & & 63 & 21 \\
\hline Metal head, shovel spear & 43 & 9 & 19 & 32 & 40 \\
\hline Dart-type & 34 & & 100 & & \\
\hline Fishing & 12 & 25 & 33 & 33 & 8 \\
\hline Miscellaneous & 8 & 50 & 12.5 & & 37.5 \\
\hline Total/average & 286 & 28 & 23 & 28 & 21 \\
\hline
\end{tabular}

Source: Recalculated from data collected by Berryman (1980).

The predominant spear form in eastern Arnhem Land was a composite spear, with a long, simple shaft used with a variety of detachable hardwood, stone or metal heads. This is a different technology to that found in north-western Australia, where dart-type forms (reed shaft plus long hardwood head without barbs) were the most common (Falkenberg 1968: 21-3). In Arnhem Land, the small dart-type spears with plain hardwood heads represent a specialised fighting/feuding spear technology based on low mass and high velocity. They are the single spear form that utilises more of the potential of spear-throwerbased projectile technology. Aboriginal trading networks were significant in providing access to the dart-type spears, which were traded from western and central Arnhem Land. In north-western Western Australia, they were used for a variety of hunting and defensive tasks and were the spear form to which small projectile points were attached (Akerman 1978; Falkenberg 1968). Although not produced locally, they fulfilled a significant role in the east Arnhem Land social economy in terms of feuding.

\section{Discussion}

There is every indication that the requirements of hunting, fighting and defence created selective pressures leading to innovation in the Aboriginal projectile armoury. In the case of the east Arnhem Land spears considered above, however, such selective pressures have not resulted in the replacement of less by more efficient forms of spear technology, as Peterson predicted. The Thomson collection does not support the idea of replacement of one form 
with another through substitution. Instead, existing forms of technology were retained alongside the new forms, with adjustments being made to all types of spears, including heavy one-piece spears, to make them spear-thrower capable. Aborigines in eastern Arnhem Land appear to have been conservative in discarding existing forms or replacing them with newer ones. This is likely to be a response to selective pressures involving mobility, access to raw materials and the necessity for each man to produce weapons that were effective for a variety of hunting, defence and fighting purposes. The outcome was probably sub-optimal, but still one that clearly fell within the tolerances required. In terms of complexity, specialised forms relate to the exploitation of marine and river environments (fishing spears and harpoons - not discussed here) and to the use of dart-type spears for feuding - something of an east Arnhem Land specialisation in itself.

Over the past decade or so, archaeologists have explored the manner in which artefact style and function interact. The analysis conducted here is relevant to these discussions in that this collection of spears shows considerable variation where stylistic and functional aspects were clearly intertwined. While all of the spears discussed are capable of fulfilling a variety of fighting and hunting tasks, the existence of this variety of forms suggests that they might not have fulfilled exactly the same function. It is likely that skills, means, needs, access to materials and trading opportunities might have varied between individual men and between groups across Arnhem Land. Spears with hardwood shafts could have had qualities of strength, durability and easy access that compensated for the additional time required to reduce them to an acceptable thickness and weight. These factors could explain their retention once lighter wood shafts became available.

Far-reaching changes in Aboriginal projectile technologies began about 5000 years ago with the first appearance of stone points in the archaeological record and with the adoption of the spear-thrower. These innovations are linked because small stone heads are too light to provide the weight stability needed for hand-thrown spears and hence require the presence of a spear-thrower. As such, they mark the time when Aboriginal projectile technologies were redesigned to accommodate these changes. Cundy (1989: 75) observes that the unifying factor in spear manufacturing after that time would appear to be load-bearing limitations involved in the use of lath and cylindrical spear-throwers, together with limitations on the weight of both spears and spear-throwers in the interest of portability.

Australian archaeologists generally work in terms of a sequence of historical changes in spear forms: from heavy hand-thrown spears to lighter spearthrower-capable forms; from one-piece to composite spears with detachable heads; and finally, innovations in terms of wood, stone and metal-tipped spears 
(Walsh and Morwood 1999). Explaining why innovations occurred in some areas but not in others involves quite complicated geographical, historical and sociological factors. It is true that Aborigines on Bathurst and Melville islands were able to hunt and defend their families using heavy, one-piece hand-thrown hardwood spears. Similarly, the composite hardwood-headed spears in the Thomson collection were also capable of performing the range of tasks required of them. To this extent, none of the innovations listed above would appear to be strictly 'necessary'. It is also true, however, that Peterson was applying an overly restrictive definition of what might be functionally necessary. Necessity is as much socially as environmentally determined.

The information from Thomson's east Arnhem Land collection allows us to consider the circumstances under which small projectile points might have been added to the tool kit. First, in a similar fashion to the large blade spearheads discussed above, small projectile points were almost certainly added to an existing spear technology in which spears with wooden shafts and wooden heads continued to be made. Second, the introduction of stone spear points would have occurred at about the same time as adjustments were being made to accommodate the use of spear-throwers, making all spear forms capable of performing hunting and fighting tasks. Third, spears with stone heads could have conferred some other advantage. Aboriginal meanings, as in the case of the stone spearheads from Ngilipitji quarry, could have played a role here, possibly through giving their users some form of ideological advantage or by demonstrating the skills of their manufacturers (Jones and White 1988). Finally, it can be concluded that the introduction of spear-throwers and stone projectile points did not cause a revolution in Aboriginal projectile technologies so much as stimulate a series of adjustments to the existing technology.

The analysis of the spears in the Thomson collection has furthered our understanding of technological and social factors involved in innovation in Aboriginal projectiles in particular, and Aboriginal technologies in general. The changes in spear shafts, head forms and attachments reveal considerable knowledge and adaptation of available materials. These changes were additive and cumulative, and to this extent, directional. The question of whether Aboriginal technologies were moving in the direction of greater efficiency, however, cannot be answered through a consideration of spear forms on their own. This requires analysis of a fuller range of Australian material technologies before reliable conclusions can be drawn. Peterson's work on technological changes in Aboriginal Australia represented an early approach to these problems. The present study takes these questions further, demonstrating that in order to understand how innovations occur, a wide range of factors must be taken into consideration. Ultimately, such studies could also provide us with a greater knowledge of the nature of change within Aboriginal society in general. 


\section{Acknowledgments}

I would like to thank the following for their assistance with this research: Mike Green, Melanie Raberts, Rob McDonald and Lindy Allen, Melbourne Museum; the Trustees of the Donald Thomson collection for access to Thomson's field notes and for permission to use this material; Annette Berryman for access to her original data sheets; Daniel Parker for generating the tables and diagrams; and Peter Quin and Briar Sefton for the illustrations. The research was carried out with the support of the Department of Anthropology, University of Auckland, the Archaeology Programme of the School of European and Historical Research, La Trobe University, and Museum Victoria. I was greatly assisted in Melbourne by Dr Viji and Margaret Krishnapillai and throughout by Jenny Miles.

\section{References}

Akerman, K. 1978. Notes on the Kimberley stone-tipped spear focusing on the point hafting mechanism. Mankind 11: 486-89.

Allen, H. 1994. The distribution of large blades (leilira): evidence for recent changes in Aboriginal ceremonial exchange networks. In P. McConvell and N. Evans (eds), Archaeology and Linguistics: Understanding Ancient Australia, pp. 357-76. Melbourne: Oxford University Press..

Allen, L. 2008. Tons and tons of valuable material: the Donald Thomson collection. In N. Peterson, L. Allen and L. Hamby (eds), The Makers and Makings of Indigenous Australian Museum Collections, pp. 387-418. Carlton, Vic.: Melbourne University Press.

Altman, J. and M. Hinkson, 2007. Mobility and modernity in Arnhem Land. Journal of Material Culture 12: 181-203.

Berndt, R. M. and C. H. Berndt, 1964. The World of the First Australians. North Sydney: Ure Smith.

Berryman, A. 1980. Material Culture: A Case Study on Spears. Honours Thesis, Department of Prehistory, La Trobe University, Melbourne.

Cundy, B. J. 1989. Formal variation in Australian spear and spearthrower technology. BAR International Series 546.

Davidson, D. S. 1934. Australian spear-traits and their derivations. Journal of the Polynesian Society 43: 41-72, 143-62. 
Davidson, D. S. 1936. The spearthrower in Australia. Proceedings of the American Philosophical Society 76: 445-83.

Falkenberg, J. 1968. Spyd og kastetraer fra murinbataene i Nord-Australia. University of Oslo Ethnographic Museum Yearbook 1968: 15-38. B. Cundy and Kim Akerman (trans.).

Franklin, D. C. 2008. Taxonomic interpretations of Australian native bamboos (Poaceae: Bambuseae) and their biogeographic implications. Telopea 12: 17991.

Jones, R. and N. White, 1988. Point blank: stone tool manufacture at the Ngilipitji quarry, Arnhem Land, 1981. In B. Meehan and R. Jones (eds), Archaeology with Ethnography: An Australian Perspective, pp. 51-87. Canberra: Department of Prehistory, Research School of Pacific Studies, The Australian National University.

Levitt, D. 1981. Plants and People: Aboriginal Uses of Plants on Groote Eylandt. Canberra: Australian Institute of Aboriginal Studies.

Meehan, B. and R. Jones (eds), 1988. Archaeology with Ethnography: An Australian Perspective. Canberra: Department of Prehistory, Research School of Pacific Studies, The Australian National University.

Mulvaney, J. and J. Kamminga, 1999. Prehistory of Australia. St Leonards, NSW: Allen \& Unwin.

Peterson, N. 1968. The pestle and mortar: an ethnographic analogy for archaeology in Arnhem Land. Mankind 6: 567-70.

Peterson, N. 1970. The importance of women in determining the composition of residential groups in Aboriginal Australia. In F. Gale (ed.) Women's Role in Aboriginal Society, pp. 9-16. Canberra: Australian Institute of Aboriginal Studies.

Peterson, N. 1971. Open sites and the ethnographic approach to the archaeology of hunter-gatherers. In D. J. Mulvaney and J. Golson (eds), Aboriginal Man and Environment in Australia, pp. 239-48. Canberra: The Australian National University Press.

Peterson, N. 1973. Camp site location among Australian hunter-gatherers: archaeological and ethnographic evidence for a key determinant. Archaeology and Physical Anthropology in Australia 8: 173-93.

Peterson, N. 1976. Ethno-archaeology in the Australian iron age. In G. de G. Sieveking, I. H. Longworth and K. E. Wilson (eds), Problems in Economic and Social Archaeology, pp. 265-75. London: Duckworth. 
Rigsby, B. and N. Peterson, 2005. Donald Thomson: The Man and Scholar. Canberra: Academy of the Social Sciences in Australia.

Specht, R. L. 1958. An introduction to the ethno-botany of Arnhem Land. In R. L. Specht and C. P. Mountford (eds), Records of the American-Australian Expedition to Arnhem Land. Volume 3, pp. 479-503. Carlton, Vic.: Melbourne University Press.

Specht, R. L. 2006. Aboriginal plant names in northeast Arnhem Land: Groote Eylandt-Enindilyakwa language; Yirrkala-Rirratjingu language. Aboriginal Studies 2006/1: 63-7.

Spencer, W. B. 1915. Guide to the Ethnological Collections, National Museum of Victoria. Melbourne: Victorian Government Printer.

Stahl, A. B. 1993. Concepts of time and approaches to analogical reasoning in historical perspective. American Antiquity 58: 235-60.

Thomson, D. F. 1939. The seasonal factor in human culture. Proceedings of the Prehistoric Society 5: 209-21.

Thomson, D. F. 1949. Economic Structure and the Ceremonial Exchange Cycle in Arnhem Land. London: Macmillan.

Thomson, D. F. 2003. Donald Thomson in Arnhem Land. Compiled and introduced by Nicolas Peterson. Carlton, Vic.: The Miegunyah Press.

Tindale, N. T. 1925. Natives of Groote Eylandt and of the west coast of the Gulf of Carpentaria. Records of the South Australian Museum 3: 61-134.

Yunupingu, B., L. Yunupingu-Marika, D. Marika, B. Marika, B. Marika, R. Marika and D. Wightman, 1995. Rirratjingu ethnobotany: Aboriginal plant use from Yirrkala, Arnhem Land, Australia. Northern Territory Botanical Bulletin No. 21, Conservation Commission of the Northern Territory, Darwin.

Walsh, G. L. and M. J. Morwood, 1999. Spear and spearthrower evolution in the Kimberley region, NW Australia: evidence from rock art. Archaeology in Oceania 34: 45-58.

Warner, W. L. 1937. A Black Civilization: A Social Study of an Australian Tribe. Revised edition. Chicago: Harper and Brothers Publishers.

White, C. and N. Peterson. 1969. Ethnographic interpretations of the prehistory of western Arnhem Land. Southwestern Journal of Anthropology 25: 45-66.

White, J. P. and J. F. O'Connell, 1982. A Prehistory of Australia, New Guinea and Sahul. Sydney: Academic Press. 